\title{
Questioning the uncritical acceptance of neuroscience in child and family policy and practice: A review of challenges to the current doxa
}

\author{
Liz Beddoe and Eileen Joy University of Auckland, Aotearoa New Zealand
}

\begin{abstract}
INTRODUCTION: Recent directions in child and family policy in many Anglophone countries, including Aotearoa New Zealand, are underpinned by the adoption of prevention science which is used to justify state interventions into the lives of families deemed "vulnerable" or "troubled".

METHODS: We conducted an examination of trends, firstly examining recent child welfare and protection policy. We discuss the science that underpins significant changes in policy and explore how this use of the available science dovetails with the dogma of the Western neoliberal agenda.
\end{abstract}

FINDINGS: The invocation of science in the struggle to reduce child maltreatment may be reassuring to politicians, policy developers and practitioners alike but a critical analysis is largely missing in the discourse in Aotearoa New Zealand.

CONCLUSIONS: Neuroscience is adopted largely uncritically in social policy in relation to child welfare and child protection. It can contribute to policy but other knowledge from social science findings about contextual factors in child maltreatment such as poverty, racism and class-based assumptions about parenting norms must not be ignored in social work practice.

KEYWORDS: early intervention, neuroscience, social policy, social work, child welfare, child protection

Child maltreatment is an enduring and intensely political social issue. Its presence in our society evokes many intense emotions and, as such, it becomes a political issue where emotion can drive our response (Warner, 2015). The death of Christopher and Cru Kahui in June, 2006 led to nationwide concern and reignited moral panic about how children and babies are treated in Aotearoa New Zealand (Beddoe, 2015). Their deaths were instrumental in the development of a discussion paper on vulnerable children (Bennett, 2011), the subsequent "Children's Action Plan" (New Zealand Government, 2012a), and the "White Paper for Vulnerable Children"
(New Zealand Government, 2012b, 2012c); then followed the Vulnerable Children Act 2014. Subsequent policy changes, including a vast, and ongoing re-structuring of the Aotearoa New Zealand child protection and welfare system (Modernising Child Youth and Family Expert Panel, 2016), are evidence of both "neuroscientism" and a deepening Western trend in intensive parenting that elevates middle-class parenting to that of an "ideal parenting state". This obscures structural issues, demonises other parenting styles and hides embedded classist, sexist and racist discourses by invoking science (Edwards, Gillies, \& Horsley, 2016; Gillies, 2013; Hyslop, 2013; Jensen, 2010; Keddell, 2016;
AOTEAROA NEW ZEALAND SOCIAL WORK 29(1), 65-76.

CORRESPONDENCE TO: Liz Beddoe e.beddoe@auckland.ac.nz 
Lowe, Lee, \& Mcvarish, 2015a, 2015b; Nadesan, 2002; Wall, 2010; Wilson, 2002) and, in particular, neuroscience (Broer \& Pickersgill, 2015; Bruer, 1999; Featherstone, Morris, \& White, 2013; France, 2012; Macvarish, 2014a, 2014b; Macvarish, Lee, \& Lowe, 2015; Thompson \& Nelson, 2001; Wastell \& White, 2012; White \& Wastell, 2013, 2015).

Whilst the deaths of the Kahui twins were, without question, tragic, their deaths (and the deaths of other children before and after) have been used to advocate for specific policy changes. It is not our position that policy changes were not required; rather, we argue that these specific policies and actions must be contextualised against a backdrop of other Anglophone nations where similar trajectories of tragic cases have led to reform. Ten years later, it is possible to view the aforementioned policy documents and compare those with international trends in order to see with which other discourses these policies are aligned. Drawing on international literature, we explore what might be learnt about the discourses around parenting and societal issues that are operating in Aotearoa New Zealand, especially the reification of neuroscience, and ask: how solid is the scientific base upon which these policies and societal trends rely, and how might social workers within both child protection and welfare, in Aotearoa New Zealand respond?

Aotearoa New Zealand is not isolated in its drive for science-based policy that recommends early intervention in the lives of families and children, nor is it something that started in 2006 with the death of the Kahui twins; rather, that event can be seen as a tipping point. In 2002, Wilson (2002), somewhat prophetically, noted that, in speaking of the growing state intervention in at-risk families, media had a propensity for depending on the "lurid" (p. 197) details of individual cases and how that leads to limited understandings of the multifactorial nature of these incidents. Hyslop (2013), more recently, observed how both the
United Kingdom (UK) and Aotearoa New Zealand have a tendency to develop reports "against a background of perceived failings in their respective child protection systems, particularly the deaths of vulnerable children" (p. 4). In referencing the English context, Parton (2016a) notes that, with this climate, came a push towards utilising knowledge about both the effects and causes of harm, with specific attention paid to the early months of life. Further, in a report linking articles critical of this drive towards, specifically, neuroscientific policy, LloydJones (2013), and Featherstone et al. (2013) note that the death of Peter Connelly in England in 2007 was a similar tipping point with one of the results being the "Munro Review" of 2011. Smeyers (2010) notes, like Wilson (2002) that the "Baby P" case led to media and public outrage (Warner, 2015). Smeyers further cautions that state intervention will never be able to prevent all deaths and any knee-jerk reaction may result in increased surveillance with the added reminder that such hasty solutions often beget other, unforeseen, problems.

Observation of hasty policy reactions led White and Wastell (2013) and Wastell and White (2013) to critique a government funded review of current research on child development and maltreatment for family justice professionals which was intended to provide an evidence base for judicial decision-makers (Brown \& Ward, 2012). The basis of their critique was that it: lacked balance (it made no mention of any controversies in neuroscience findings); conflated statistical significance and predictive validity; relied on contested concepts such as the "myth of the first three years" (a concept debunked by Bruer, 1999); was not sufficiently rigorous; and the case studies were "dangerously inflammatory and full of fictitious neurospeculation" (Wastell \& White, 2013, p. 10). In response, Ward and Brown (2013) contended that Wastell and White had been "emotive" and that they had failed to find any "serious flaws" (p. 1181). Regardless of the language employed by either camp, the report from 
Brown and Ward (2012) is part of a growing trend in English policy to use neuroscience to back up policy ${ }^{1}$.

Macvarish (2014a) notes that a trend in policy relying on neuroscience began in the United States (US) in the 1990s and the UK in the 2000s. Bruer (1999) details how the Clinton administration (informed by organisations such as the Rob Reiner Foundation) spearheaded a drive to consider parenting based on science. Bruer, who attended a White House conference showcasing such science, noted that early parenting experiences were being linked to later undesirable outcomes such as substance abuse, violence and anti-social behaviour. The underlying tenet of the conference was that, while speakers were careful not to write children off, early intervention was the way to solve such societal ills, and early patterns were enduring and very hard to alter as the child grew up. He further observed that there was only one neuroscientist present yet almost all the speakers had invoked neuroscience as justification for a raft of policy interventions. While this policy direction had been simmering throughout the 1990s and before, it was evidence of a country-wide move to validate a specific interpretation of neuroscience findings (Bruer, 1999).

\section{Neuroscience, neuromania and neuroscientism}

Bruer (1999), Wastell and White $(2012,2013)$ and White and Wastell $(2013,2015)$, noting the heavy underpinning of neuroscience, argue that, if policy is so informed by this science, then the science itself bears scrutiny. Indeed, many reviews of neuroscientific findings and how they relate to childhood, parenting, abuse and maltreatment are cautious in recommending policy directions. Belsky and de Haan (2011), in reviewing the relationship between parenting and brain

1 For a more thorough and comprehensive review of the way neuroscience is shaping child protection and welfare policy please see: White \& Wastell (2015). development, note that one would have to believe in "magic" (p. 409) to conclude that parenting did not have any effect on either behaviour or brain structure. However, they urge caution on several grounds, namely: current knowledge is limited; extreme caution must be used when implying causation; and that current research (due to compounding factors) might be overstating the impact of abuse. Furthermore, the ubiquitous reference to the institutional neglect suffered by Romanian orphans, as it was extreme and isolated, is not comparable to cases experienced by child protection workers:

[B]ecause such deprivation involves much more than just limitations in caregiving, it is no doubt mistaken to equate it completely with - and thus expect exactly the same effects of the kind of parental neglect typically encountered by child protection workers dealing with troubled families. (Belsky \& de Haan, 2011, p. 414)

Belsky and de Haan also caution that there have been no studies done using neuroimaging over time and thus existing neuroimages cannot show development, a point also made by Munro and Musholt (2014). As Schmitz and Höppner (2014) state, neuroimages are merely a moment in time, they cannot tell us anything about nature or nurture-or even the combination thereofall they can indicate is what is happening right at that time. Twardosz and Lutzker (2010) similarly advise that, "the precise effects on the human brain and the extent to which they might be reversed or modified by intervention are still far from clear" (p. 66).

How then, do these tentative findings contrast with what is written in Aotearoa New Zealand government policy documents? Both the Children's Action Plan (New Zealand Government, 2012a) and Volume 1 of the White Paper (New Zealand Government, 2012b) rely on the research gathered in Volume 2 of the White Paper 
(New Zealand Government, 2012c) and so it is from this volume that the following example is drawn. When contrasting this text on stress and the developing child with the cautionary findings of Tarullo and Gunnar (2006) and McCrory, De Brito, and Viding (2010), it becomes clear that the report paints a far more conclusive view of the evidence:

Chronic high levels of cortisol - one of the most important stress hormones result in reduced brain volume and may cause neurons to die. This may also reduce connectivity in the brain. It can cause children to develop a low threshold for stress, which may render them overly reactive to adverse experiences. It also impairs learning by reducing growth in the hippocampus, which is a key structure for memory. Collectively these processes tend to reduce the moderating role of the cortex, leading to underregulation of behaviour. (New Zealand Government, 2012c, p. 14)

This report goes on to emphasise that these effects can be mitigated through "positive nurturant experiences" (New Zealand Government, 2012c, p. 14) but it stresses that "traumatic and stressful events can have profound negative effects on development at a basic biological level, by encoding negative experience within the brain and over-wiring the stress response system" (2012c, p. 14). We suggest that, despite the qualifiers, "may" and "can," the reader would be left with the belief that such a relationship is more certain than hypothetical.

Other reports which have fed into government policy include statements such as the following:

Frequent or sustained activation of brain systems that respond to stress can heighten vulnerability to a range of behavioural and physiological disorders over a lifetime. (New Zealand House of Representatives Health Committee, 2013, p. 9)
The evidence is very strong; the first few years of life from pre-conception are fundamentally important for a broad range of child health outcomes, and for the achievements of children as adolescents and adults. (Ministry of Health, 2011, p. 6)

The following two extracts are both from "Puberty and adolescence: Transitions in the life course" a report into "reducing social and psychological morbidity during adolescence" and are from the Office of the New Zealand Prime Minister's Chief Science Advisor (2011). Whilst this paper has focused on looking at policy concerning early childhood, it is important to note, as France (2012) does with regard to Aotearoa New Zealand adolescent-focused policy, that this overemphasis on, and exaggeration of, neuroscience can appear in government policy in relation to any age group.

While most of this science is based on compelling data from animal studies, there are supportive data in humans showing that stresses and challenges early in life will change the settings of switches involved in pathways associated with social experiences and stress responses, with permanent effects. (Gluckman, Lowe, \& Franco, 2011, p. 26)

Children who are most at risk for social and emotional problems are those children who are continually exposed to one or more environmental stressors. A certain amount of stress in early childhood can be adaptive and growth promoting. However, chronic or "toxic" stress can have an adverse effect on the developing architecture of the brain. This is particularly apparent in the fetal and early childhood periods. (Wouldes, Merry, \& Guy, 2011, p. 38)

Such policy discourse is an example of what Tallis (2011) calls "neuromania": "the appeal to the brain, as revealed through the latest science, to explain our behavior" (p. 5). Both Tallis, and Nadesan (2002), identify 
this explanation of human behaviour as a new version of social Darwinism: a way of explaining and legitimising social hierarchies by falling back on biology. Tallis (2011) argues that it is not neuroscience itself which is at issue here, rather it is "neuroscientism", explained by Macvarish et al. (2015) as "the fetishisation of a neuroscientific vocabulary as a source of authority to underpin policy claims-making" (2015, p. 254).

Bruer (1999) identifies key concerns over these policy trends which revolve around three key areas:

- A promotion of the early years (largely $0-3$ ) as a time of heightened and explosive brain growth not replicated in subsequent years. Bruer points out that many people have contested these claims and evidence of brain size is no evidence of brain capacity, or learning potential.

- $\quad$ That there are a large number of critical (often described as sensitive in documents) periods in those early years whereby formative experiences function as a biological make or break and cannot be remedied in later years. With recourse to the literature, Bruer (1999) shows that the only areas in which this has been definitively proven is in the areas of language acquisition and aspects of visual development. He contends that critical periods are atypical for human development, and must be rare. This must be so given the diversity of environments that children are born into as it would be evolutionarily unwise for critical periods, which rely on certain and expected environmental stimuli, to be so prevalent in our development.

- $\quad$ That providing a child with a stimulating environment in the early years can boost brain power with lifetime effect. Again, through recourse to literature, Bruer demonstrates that the evidence for such claims is limited.
Whilst not all the above strands are evident in policy documents, it is important to note that all are present in discourse around neuroscience and parenting in the wider Aotearoa New Zealand context. There are several examples of note. The Ministry of Health's (2015) latest edition of the Well Child booklet given to all parents of newborns, advises parents that: "over the next three years the brain grows more complex and capable" (p. 196). Brainwave Trust, an Aotearoa New Zealand based advocacy organisation dedicated to looking at neuroscience (tagline "the early years last forever") claims that: "[t]here are critical and sensitive periods in brain development during which rapid changes take place, and after which it becomes difficult if not impossible to re-capture those developments" (Brainwave Trust, 2011, n.p.).

Given the strong challenges to the place of neuroscience in policy (Bruer, 1999; Wastell \& White, 2012, 2013) a deeper examination of the context of this obsession with parenting is justified.

\section{Neuro-neoliberalism}

Authors commenting on neuroscientism (Macvarish, 2014b; Nadesan, 2002; PittsTaylor, 2010; Schmitz \& Höppner, 2014; Wall, 2010) have noted that its rise coincides with neo-liberal approaches to welfare. Rose and Abi-Rached (2013) are more reserved in their analysis, preferring to conclude that this trend is simply evidence of a "'hopeful' ethos of the life sciences in contemporary societies" (p. 248). Both White and Wastell (2015) and Gillies and Edwards (2017) observe that the policy of "early intervention" has been heavily informed by Heckman, an economist who draws links between child development and later societal economic costs (see, Heckman, 2006). White and Wastell (2015) note that Heckman's research relies primarily on a small data set of three US-based studies (see Heckman \& Masterov, 2007) which further relied on Bruer's (1999) three strands of assumptions cited above. 
Heckman is cited as evidence of economic benefit in the "White Paper" (New Zealand Government, 2012b), the "Transitions Report into Adolescence" (Office of the Prime Minister's Science Advisory Committee, 2011), the recent final "Expert Report" (Modernising Child Youth and Family Expert Report, 2016), and the "Inquiry into improving child health outcomes and preventing child abuse, with a focus on pre-conception until three years of age" report from the Health Committee (New Zealand House of Representatives Health Committee, 2013). Economic discourse pervades the White Paper documents and the Expert Panel report, revealing that the main reason government is interested in how much parents "nurture/love" their children is not a good, in and of itself. This is a belief clearly articulated by Heckman and Masterov (2007) when they explicitly identify that other people justify interventions, specifically early childhood ones, as a "question of fairness or social justice" but they argue for it on "productivity grounds." (p. 2). For example:

- $\quad$ "A working breadwinner is the best form of security a family can get" (New Zealand Government, 2012b, p. 26).

- "To ensure future economic and social success, it is important that children are healthy, well nurtured and educated so they are well equipped to assume these future roles" (New Zealand Government, 2012c, p. 39).

- In citing Heckman: "forward liability (the cumulative costs across a lifetime) points to the significant fiscal and social benefits of intervening as soon as possible, when problems are less entrenched and damaging" (Modernising Child Youth and Family Expert Report, p. 10).

The examples above show how such positioning of children as resources for future capitalist acquisition creates doxa
(Bourdieu, 1977, p. 169) where "important issues remain unspoken and taken for granted." Parents in this case are held up as normal or abnormal, based on doxic, hidden, class-based assumptions with abnormal parenting to be managed in targeted services, for least cost. Crossley (2015, p. 264) writes "discourses from the state... carry more weight than others because they are official and are often accepted as being authorised and legitimate accounts" and these very deliberate links between childhood and future liability-downstream fiscal demands_riddle Aotearoa New Zealand social policy.

Pitts-Taylor (2010) notes that neoliberalism is creating a "neuronal self," one that "firmly situates the subject in a normative, neoliberal ethic of personal self-care and responsibility linked to modifying the body" (p. 639). She contends that body/ self-maintenance have become the new duties of the neoliberal citizen where, by looking after oneself one avoids being a financial liability to the state. Parton (2016b) sees this creation of the ideal neoliberal citizen when he observes that child welfare and protection have become one of many places where people need to be educated into "good behaviour and the importance of a moral obligation to work, and to manage one's family's affairs competently." (p. 8). Crucially, providing historical context, Gillies and Edwards (2017), note that these recent developments are "merely the latest incarnation of a longstanding conviction held by the rich and powerful. Specifically that there must be something inherently wrong with the minds, bodies and souls of those failing to thrive in an unfettered free market economy." (p. 19)

\section{Policy and societal intersection}

Policy is not created in a vacuum, rather it is informed by, and informs, social discourse. It is to this intersection that we now turn. In reviewing criticism of the use of neuroscience in policy and society, there are 
several broader societal themes and issues to be addressed:

1. That such policy ignores structural issues such as inequality and poverty and seeks to individualise social problems (Edwards, Gillies, \& Horsley, 2013; Gillies, 2013; Hyslop, 2013; Nadesan, 2002) and that this then legitimises classism by stealth.

2. That the public at large, of which social workers are a part, through media misrepresentations of research, are influenced by studies about the brain and have a limited understanding of neuroimaging which results in biases favouring research that mentions neuroscience directly and / or uses neuroimages to illustrate points (O'Connor \& Joffe, 2013; Petersen, 2001; Racine, Waldman, Rosenberg, \& Iles, 2010; Ramani, 2009; Thompson \& Nelson, 2001; Weisberg, Keil, Goodstein, Rawson, \& Gray, 2008).

3. That the ensuing policies and practices contribute to a new legitimisation of racist and ethnic bias (Edwards, Gillies \& Horsley, 2015; Hyslop, 2013; Wilson, 2002). Hyslop (2013), for example, points out that any reference to Māori in the White Paper documents is "selective, superficial and clichéd" (p. 5).

4. That "intensive parenting", is reviving a back to basics philosophy which essentialises women and creates a profoundly sexist view of parenting which responsibilises and biologises women and, to a lesser degree, parents (Gillies, 2013; Jensen, 2010; Lowe et al., 2015a; Macvarish, 2014a, 2014b; Nadesan, 2002; Schmitz \& Höppner, 2014; Wall, 2010).

Space does not permit fuller discussion of the many concerns identified in this review. However, the legitimisation of malignant racist and sexist discourses are worthy of much more detailed attention and will be discussed in a later article.

\section{Structural issues: minimising poverty}

In comparing the content of the White Paper (New Zealand Government, 2012b, 2012c) with the England-based "Munro Report", Hyslop (2013) notes that social inequality is not discussed unless it is within the context of denigrating welfare dependency. He posits that poverty could have been utilised as a uniting concept in discussing childhood vulnerability (see, for example, Bywaters et al., 2016), however, it has been relegated to being one of the contributing factors. It is also of note that, whilst discussion about the effects of poverty on parenting appears in most of the literature, the relationship tends to be reversed, with parenting being the "cause" of poverty and not the inverse. Nadesan (2002) points out that the parenting practices associated with good nurturing and optimal brain development are the very types of parenting typified by the middle class and only truly accessible to those with time and money. Therefore, the logic goes, those with good parenting practices have themselves been parented in such a way as to avoid poverty. Indeed, Heckman and Masterov (2007) assert the link between money and parenting by constantly referring to "better" outcomes for children of wealthier families without once considering broader structural issues; for them, it is all about an increase in "non-traditional families" (p. 2).

Edwards et al. (2013) note that individualising societal problems through the parenting of the child and future adult, allows politicians to ignore societal questions about class and poverty. Further to this, it plays into middle-class anxieties about social mobility; for when middle-class parenting styles are reified in policy documents, it serves as a warning that your children's social standing is up to you as a parent. They point out that:

The current policy preoccupation with the nurturing practices of poor families relies on a meritocratic construction of the 
wealthy and privileged as having better developed brains. Success is naturalised and unproblematically correlated with brain structure and intelligence. From this perspective the solution to poverty is to make people smarter - children of the poor can then think themselves out of their predicament. Recognition of systematic, structurally engrained inequality merely hold back the power of the individual brain, creating a psychological block that circumscribes achievement and justifies inertia. This is certainly an optimistic standpoint, but it's a cruel optimism devoid of any basis in real experience of hardship. (p. 12)

It is then not too much of a stretch for researchers (Edwards et al., 2013, Gillies \& Edwards, 2017) to note the similarities between this approach and eugenics. It is simply more effectively hidden than in the past.

\section{Misrepresentation of neuroscience in the news media}

Social workers do not exist in a vacuum; rather they are influenced by, and influence, society and, much like other citizens they are affected by how the media presents information. In Aotearoa New Zealand having access to source material to check research, or conduct one's own research, is often limited to academic institutions, thus social workers here are frequently forced to rely on second-hand interpretations of source material, often through media, popular literature and training opportunities. This limited exposure to peer-reviewed journals then, provides a very specific context in which the media has a greater influence over local social workers than in some other Anglophone countries where access to literature is easier. Scholars have demonstrated that the societal dissemination of neuroscience findings through media or otherwise is not without problems. Thompson and Nelson (2001) and Ramani (2009) note that public interest in human behaviour is strong, leading to media reporting such findings more frequently than findings within what are traditionally called the "hard sciences." Thompson and Nelson (2001) also observe that such research is prone to "campaign journalism" (p. 5), a process whereby lobbyists and politicians aim to increase public commentary on particular policies - many of which involve aspects of human behaviour. They warn that there needs to be a closer relationship between journalists and neuroscientists to avoid such errors but also suggest that there is temptation for scientists to remain silent to maintain publicity and generate funding, even if the publicity is not accurate.

Petersen (2001) in Australia, Racine et al. (2010) and O'Connor, Rees, and Joffe (2012) in the UK have reviewed how brain science and/or parenting have been portrayed in selected Western newspapers. All three studies indicated that neuroscience findings were distorted and that there was little commentary critical of the findings. Racine et al. (2010) found that no mention was made of sample sizes, funding sources or the need for replication in any of the analyses. Such unquestioning support of the neuroscience reported could well undermine public support for non-biological approaches to these issues. Petersen (2001) found that there was little support ever given to nonbiological or multi-factorial explanations for any of the issues presented in the neuroscience-based articles. O'Connor et al. (2012) also observed that "media coverage of neurobiological differences reinforced divisions between social groups and was presented in stereotype-consistent ways" (p. 223).

Of equal concern is evidence that the general public attributes greater authenticity and reliability to explanations of behaviour that include neuroscience and/or contain neuroimages. Weisberg et al. (2008) found such a relationship between the placement of neuroimages in stories about a psychological phenomenon and favourability ratings. This is of particular concern when neuroimages such as the brain scan of a "normal" child and a "neglected" child (Perry, 2002; Perry \& 
Pollard, 1997) have been widely used in policy and parenting literature and media (Healy, 2015; Wastell \& White, 2013; White \& Wastell, 2013). Brainwave Trust provides a link on their website (http:/ / www.brainwave.org.nz/wpcontent/uploads/2012/05/MindBrain.pdf) to the Perry (2002) article which contains the neuroimage in question. The image, as pointed out by Healy (2015) is devoid of a detailed case history and fails to provide a comparison scale, both of which would be evidence of academic rigour.

\section{Implications for social work practice in Aotearoa New Zealand}

How then should social workers in Aotearoa New Zealand tackle the calls from their employers (and the public) to use neuroscience findings in their practice? How should social workers engage with literature about "brain science" in their day-to-day lives without being unwittingly seduced by the hype and biases that pervade it, and the accompanying media coverage? There are several different suggestions about how best to integrate such knowledge-some are more enthusiastic about the potential for neuroscience and social work than others.

Plafky (2015) provides an analysis of why neuroscience is over-emphasised in social work and how we might guard against it. He observes that there is a bias towards thinking that "evidence-based practice" and research on brains go hand-in-hand. Such bias is, perhaps, an inevitable result of a lack of access to source material, especially critical in the Aotearoa New Zealand context (with a reliance on secondary material or trainers who are brought in for professional development) combined with a lack of education on how to engage with neuroscience findings in a critical manner.

Green and McDermott (2010) and Sayre and Walker (2014) assert that social work must embrace the findings of neuroscience and evolutionary theory (evolutionary psychology in the latter case) in an effort to stay current. Green and McDermott observe that person-in-environment (PIE) theory has been well utilised, but criticise it for having little explanatory power; in summary, they contend that PIE sites the person in a particular environment but does not explain that person's journey into that particular environment. Sayre and Walker conclude that the marriage of neuroscience and evolutionary psychology would be beneficial and that, "once the neurophysiological impacts of injustice and interpersonal harm are understood, the profession of social work has a clear theoretical foundation for social justice advocacy" (2014, p. 970). However, a key proviso in examining these contributions is that neither Green and McDermott, nor Sayre and Walker, address the inherent problems raised by other authors about the discourses inherent in many presentations of neuroscience.

Whilst not explicitly advocating for social work, Stirling (2011) nonetheless provides a rigorous framework that social workers could consider in assessing neuroscience findings. He demonstrates that there are lessons to be learned from the application of other "new" sciences and notes that "levels of knowledge that are sufficient for a technology to meet initial narrow practice goals, are rarely sufficient to predict the full range of eventual indirect impacts" (p. 87). He cautions against falling for enthusiastic displays of new science and provides a list of syndromes to look for in examining neuroscience findings. Stirling suggests examining findings using a "social appraisal" (p. 93) method which comprises three strands, which bear examination in some detail:

- Responsibility: the governance of neuroscience should be independent and there should be drives to avoid a hierarchy of sciences dominated by it; that other avenues of research amongst other disciplines should also be considered. 
- Precaution: there should be no automatic assumption of benefits claimed; he points out that a lack of evidence of harm is not evidence of no harm.

- Engagement: there should be open and accountable public engagement with non-expert voices included (pp. 94-96).

Social workers in Aotearoa New Zealand would be well advised to consider these strands when asked to implement or assess new policy directives and guidelines. An example of the significance of Stirling's recommendations is to be found in France (2012). He notes that Gluckman, the New Zealand Prime Minister's Chief Science Advisor, demonstrates a documented bias against social sciences. He states that Gluckman (Office of the Prime Minister's Science Advisory Committee, 2011) characterises the social sciences as "'dogma' driven, 'ideologically' shaped and 'anecdotal'" (p. 92). Our view is that, in the case of current child welfare policy, the dogma which drives the neoliberal agenda is wedded to neuroscientism.

Finally, it is worth considering the approach advocated by Munro and Musholt (2014), a balanced approach that advises that neuroscience is not to be ignored and, whilst acknowledging many of the critiques cited earlier, they conclude that, with an interdisciplinary approach, such problems have the potential to be mitigated. They note that neuroscience cannot possibly integrate all of the prior, current and future social science findings about child maltreatment and so it is critical that there is multidisciplinary integration. They also observe that, sadly, very few people currently "feel competent to challenge neuroscientific assertions and so intelligent debate can be stifled" (p. 8), and that, even if we agree that maltreatment of children causes irreversible brain damage, there is no automatic solution as to what the best intervention might be (whether that be family wraparound support or child removal). That "integration space" is the space therefore that social work can, and must occupy.
As intermediaries between people and the state, we have a unique position from which to argue for a more contextualised understanding of the "findings" of neuroscience. Social workers have an intimate knowledge of the multi-factorial nature of social problems, something that is sadly lacking in the current (mis)application of neuroscience to policy. Thus, whilst child deaths evoke strong emotions and invoke calls for action, we must ensure they do not lead to the uncritical use of neuroscience as a basis for more state surveillance and intervention in parenting when such interventions seem to rely on a contested and nuanced research base.

\section{References}

Beddoe, L. (2015). Making a moral panic: "Feral families", family violence and welfare reforms in New Zealand. Doing the work of the state? In V. E. Cree, G. Clapton, \& M. Smith (Eds.), Moral panics in theory and practice: Gender and family moral panics in theory and practice (pp. 55-65). Bristol, UK: Policy Press.

Belsky, J., \& de Haan, M. (2011). Annual research review: Parenting and children's brain development: The end of the beginning. Journal of Child Psychology and Psychiatry, 52(4), 409-428.

Bennett, P. (2011). Green paper for vulnerable children [Press release]. Retrieved from http://www.beehive.govt. $\mathrm{nz} /$ release/green-paper-vulnerable-children

Bourdieu, P. (1977). Outline of a theory of practice. Cambridge, UK: Cambridge University Press.

Brainwave Trust. (2011). Wiring the brain. Retrieved from http://www.brainwave.org.nz/wp-content/uploads/2014/06/ Wiring-the-Brain_flyer-28.5.14_web.pdf

Broer, T., \& Pickersgill, M. (2015). Targeting brains, producing responsibilities: The use of neuroscience within British social policy. Social Science and Medicine, 132, 54-61. doi:http://dx.doi.org/10.1016/j. socscimed.2015.03.022

Brown, R., \& Ward, H. (2012). Decision-making within a child's timeframe: An overview of current research evidence for family justice professionals concerning child development and the impact of maltreatment. Retrieved from https://www.gov.uk/government/uploads/system/ uploads/attachment_data/file/200471/Decision-making_ within_a_child_s_timeframe.pdf

Bruer, J. T. (1999). The myth of the first three years. New York, NY: The Free Press.

Bywaters, P., Bunting, L, Davidson, G., Hanratty, J., Mason, W., McCartan, C., \& Steils, N. (2016). The relationship between poverty, child abuse and neglect: An evidence review. Joseph Rowntree Foundation (2016). Retrieved from https://www.jrf.org.uk/report/relationship-betweenpoverty-child-abuse-and-neglect-evidence-review

Crossley, S. (2015). "Realising the (troubled) family", "crafting the neoliberal state". Families, Relationships and Societies, 5, 263-279. doi:10.1332/204674315X14326465757666 
Edwards, R., Gillies, V., \& Horsley, N. (2013, June). Rescuing Billy Elliot's brain: Neuroscience and early intervention. In Brain Science and Early Intervention: Joint meeting of the BSA childhood study group and the BSA families and relationships study group. Goldsmiths, University of London, UK.

Edwards, R., Gillies, V., \& Horsley, N. (2015). Brain science and early years policy: Hopeful ethos or "cruel optimism"? Critical Social Policy, 35(2), 167-187. doi:10.1177/0261018315574020

Edwards, R., Gillies, V., \& Horsley, N. (2016). Early intervention and evidence-based policy and practice: Framing and taming. Social Policy and Society, 1-10.

Featherstone, B., Morris, K., \& White, S. (2013). A marriage made in hell: Early intervention meets child protection. In D. Wastell, S. White, \& A. Lorek (Eds.), The child's timeframe-A neuro scientific perspective (pp. 8-11). Retrieved from http://www.14gis.co.uk/

France, A. (2012). "It's all in the brain": Science and the "new" construction of the youth problem in New Zealand. New Zealand Sociology, 27(2), 76-95

Gillies, V. (2013,May). From baby brain to conduct disorder: The new determinism in the classroom. Gender and Education Association Conference (Vol. 25). London.

Gillies, V., \& Edwards, R. (2017). "What about the children?" Re-engineering citizens of the future In J. Pykett, R. Jones, \& M. Whitehead (Eds.), Psychological governance and public policy Oxon, UK: Routledge.

Gluckman, P., Low, F., \& Franco, K. (2011). Puberty and adolescence: Transitions in the life course. Office of the Prime Minister's Science Advisory Committee Report, Improving the transition: Reducing social and psychological morbidity during adolescence: $A$ report from the Prime Minister's Chief Science Advisor (pp. 19-34). Auckland, NZ: Office of the Prime Minister's Science Advisory Committee.

Green, D., \& McDermott, F. (2010). Social work from inside and between complex systems: Perspectives on personin-environment for today's social work. British Journal of Social Work, 40(8), 2414-2430. doi:10.1093/bjsw/ bcq056

Healy, K. (2015). After the biomedical technology revolution: Where to now for a bio-psycho-social approach to social work? British Journal of Social Work, 1-17. doi:10.1093/ bjsw/bcv051

Heckman, J. J. (2006). Skill formation and the economics of investing in disadvantaged children. Science, 312(5782), 1900-1902.

Heckman, J. J., \& Masterov, D. V. (2007). The productivity argument for investing in young children. Retrieved from: http://jenni.uchicago.edu/human-inequality/papers/ Heckman_final_all_wp_2007-03-22c_jsb.pdf

Hyslop, I. (2013). The "White paper for vulnerable children" and the "Munro review of child protection in England": A comparative critique. Aotearoa New Zealand Social Work, 25(4), 4-14.

Jensen, T. (2010). Warmth and wealth: Re-imagining social class in taxonomies of good parenting. Studies in the Maternal, 2(1), 1-13.

Keddell, E. (2016). Child protection reform and welfare reform in Aotearoa New Zealand: Two sides of the same coin? In J. Maidment \& L. Beddoe (Eds.), Social policy for social work and human services in Aotearoa
New Zealand (pp. 237-251). Christchurch, NZ: Canterbury University Press.

Lloyd-Jones, E. (2013). Foreword: The child's time frame: What the neuroscience really says. In D. Wastell, S. White, \& A. Lorek (Eds.), The child's timeframe-A neuro scientific perspective (pp. 8-11). Retrieved from http://www.14gis.co.uk/

Lowe, P., Lee, E., \& Macvarish, J. (2015a). Biologising parenting: Neuroscience discourse, English social and public health policy and understandings of the child. Sociology of Health \& IIIness, 37(2), 198-211. doi.org/10.1111/1467-9566.12223

Lowe, P., Lee, E., \& Macvarish, J. (2015b). Growing better brains? Pregnancy and neuroscience discourses in English social and welfare policies. Health, Risk \& Society, 17(1), 15-29. doi:10.1080/13698575.2014.994479

Macvarish, J. (2014a). The politics of parenting. In E. Lee, J. Bristow, C. Faircloth, \& J. Macvarish (Eds.), Parenting culture studies [Kindle DX version] (pp. 76-101). Basingstoke, UK: Palgrave.

Macvarish, J. (2014b). Babies' brains and parenting policy: The insensitive mother. In E. Lee, J. Bristow, C. Faircloth, \& J. Macvarish (Eds.), Parenting culture studies [Kindle DX version] (pp. 165-183). Basingstoke, UK: Palgrave.

Macvarish, J., Lee, E., \& Lowe, P. (2015). Neuroscience and family policy: What becomes of the parent? Critical Social Policy, 35(2), 248-269. doi:10.1177/0261018315574019

McCrory, E., De Brito, S. A., \& Viding, E. (2010). Research review: The neurobiology and genetics of maltreatment and adversity. Journal of Child Psychology and Psychiatry, 51(10), 1079-1095.

Ministry of Health. (2011). Healthy beginnings: Developing perinatal and infant mental health services in New Zealand. Wellington, NZ: Author.

Ministry of Health. (2015). Well child tamariki ora: My health book. Wellington, NZ: Author.

Modernising Child Youth and Family Expert Panel. (2016). Expert panel final report: Investing in New Zealand's children and their families. Wellington, New Zealand. Retrieved from https://www.msd.govt.nz/about-msd-andour-work/work-programmes/investing-in-children/

Munro, E., \& Musholt, K. (2014). Neuroscience and the risks of maltreatment. Children and Youth Services Review, 47, 18-26.

Nadesan, M. H. (2002). Engineering the entrepreneurial infant: Brain science, infant development toys, and governmentality. Cultural Studies, 16(3), 401-432.

New Zealand Government. (2012a). Children's action plan: Identifying, supporting and protecting vulnerable children. Retrieved from http://childrensactionplan.govt.nz/resources/ childrens-action-plan-progress-report-december-2015/

New Zealand Government. (2012b). The white paper for vulnerable children: Volume 1. Retrieved from http://www.childrensactionplan.govt.nz/resources/whitepaper/

New Zealand Government. (2012c). The white paper for vulnerable children: Volume 2. Retrieved from http://www.childrensactionplan.govt.nz/resources/whitepaper/

New Zealand House of Representatives, Health Committee. (2013). Inquiry into improving child health outcomes and preventing child abuse, with a focus on pre-conception 
until three years of age [Report of the Health Committee] Retrieved from http://www.parliament.nz/en-nz/pb/sc/ business-summary/OODBSCH_INQ_11221_1/inquiry-intoimproving-child-health-outcomes-and-preventing

O'Connor, C., \& Joffe, H. (2013). Media representations of early human development: Protecting, feeding and loving the developing brain. Social Science \& Medicine, 97, 297-306.

O'Connor, C., Rees, G., \& Joffe, H. (2012). Neuroscience in the public sphere. Neuron, 74(2), 220-226.

Office of the Prime Minister's Science Advisory Committee. (2011). Improving the transition: Reducing social and psychological morbidity during adolescence: $A$ report from the Prime Minister's Chief Science Advisor [Committee Report]. Auckland, NZ: Author.

Parton, N. (2016a). The contemporary politics of child protection: Part two (the BASPCAN Founder's Lecture 2015). Child Abuse Review, 25, 9-16.

Parton, N. (2016b). An "authoritarian neoliberal" approach to child welfare and protection? Aotearoa New Zealand Social Work, 28(2), 7-8.

Perry, B. D. (2002). Childhood experience and the expression of genetic potential: What childhood neglect tells us about nature and nurture. Brain and Mind, 3(1), 79-100.

Perry, B. D., \& Pollard, R. (1997). Altered brain development following global neglect in early childhood. Proceedings from the Society for Neuroscience Annual Meeting, New Orleans, Louisiana.

Petersen, A. (2001). Biofantasies: Genetics and medicine in the print news media. Social Science and Medicine, 52(8), 1255-1268.

Pitts-Taylor, V. (2010). The plastic brain: Neoliberalism and the neuronal self. Health, 14(6), 635-652.

Plafky, C. S. (2015). From neuroscientific research findings to social work practice: A critical description of the knowledge utilisation process. British Journal of Social Work, 1-18. doi: 10.1093/bjsw/bcv082

Racine, E., Waldman, S., Rosenberg, J., \& Illes, J. (2010). Contemporary neuroscience in the media. Social Science \& Medicine, 71(4), 725-733.

Ramani, D. (2009). The brain seduction: The public perception of neuroscience. Journal of Science Communication, 8(4). Retrieved from http://jcom.sissa.it/ archive/08/04/Jcom0804(2009)L01

Rose, N., \& Abi-Rached, J. M. (2013). Neuro: The new brain sciences and the management of the mind [Kindle DX version]. Princeton, NJ: Princeton University Press. Retrieved from https://www.amazon.com/Neuro-BrainSciences-Management-Mind/dp/0691149615

Sayre, M. M., \& Walker, R. (2014). Evolutionary theory and neuroscience: An explanatory theory for social work. Journal of Human Behavior in the Social Environment, 24(8), 966-972.

Schmitz, S., \& Höppner, G. (2014). Neurofeminism and feminist neurosciences: A critical review of contemporary brain research. Frontiers in Human Neuroscience, 8,1-10.

Smeyers, P. (2010). State intervention and the technologization and regulation of parenting. Educational Theory, 60(3), 265-270.

Stirling, A. (2011). Governance of neuroscience: Challenges and responses. Brain Waves Module 1: Neuroscience, Society and Policy, 87-97.
Tallis, R. (2011). Aping mankind: Neuromania, Darwinitis and the misrepresentation of humanity. Durham, UK: Acumen.

Tarullo, A. R., \& Gunnar, M. R. (2006). Child maltreatment and the developing HPA axis. Hormones and Behavior, 50(4), 632-639.

Thompson, R. A., \& Nelson, C. A. (2001). Developmental science and the media: Early brain development. American Psychologist, 56(1), 5-15.

Twardosz, S., \& Lutzker, J. R. (2010). Child maltreatment and the developing brain: A review of neuroscience perspectives. Aggression and Violent Behavior, 15(1), $59-68$.

Wall, G. (2010). Mothers' experiences with intensive parenting and brain development discourse. Women's Studies International Forum, 33(3), 253-263.

Ward, H., \& Brown, R. (2013). Decision-making within a child's timeframe: A response. Family Law Journal, 43 , 1181-1186.

Warner, J. (2015). The emotional politics of social work and child protection. Bristol, UK: Policy Press.

Wastell, D., \& White, S. (2012). Blinded by neuroscience: Social policy, the family and the infant brain. Families, Relationships and Societies, 1(3), 397-414. doi:10.1332/ 204674312x656301

Wastell, D., \& White, S. (2013). The child's time frame: What the neuroscience really says. In D. Wastell, S. White, \& A. Lorek (Eds.), The child's timeframe-A neuro scientific perspective (pp. 8-11). Retrieved from http://www.14gis. co.uk/

Weisberg, D. S., Keil, F. C., Goodstein, J., Rawson, E., \& Gray, J. R. (2008). The seductive allure of neuroscience explanations. Journal of Cognitive Neuroscience, 20(3), 470-477.

White, S., \& Wastell, D. (2013). A response to Brown and Ward: Decision-making within the child's timeframe. Retrieved from http://dx.doi.org/10.2139/ssrn.2325357

White, S., \& Wastell, D. (2015). The rise and rise of prevention science in UK family welfare: surveillance gets under the skin. Families, Relationships and Societies. doi:http://dx.doi.org/10.1332/204674315X14479283041843

Wilson, H. (2002). Brain science, early Intervention and 'at risk' families: Implications for parents, professionals and social policy. Social Policy and Society, 1(3), 191-202.

Wouldes, T., Merry, S., \& Guy, D. (2011). Social and emotional competence: Intervening in infancy. Office of the Prime Minister's Science Advisory Committee Report, Improving the transition: Reducing social and psychological morbidity during adolescence: $A$ report from the Prime Minister's Chief Science Advisor (pp. 35-48). Auckland, NZ: Office of the Prime Minister's Science Advisory Committee. 